SMALL INTESTINE

\title{
Ferroportin/IREG-1/MTP-1/SLC40A1 modulates the uptake of iron at the apical membrane of enterocytes
}

\author{
C Thomas, P S Oates
}

Gut 2004;53:44-49

See end of article for authors' affiliations ......................

Correspondence to: Dr P S Oates, M311 Physiology School of Biomedical and Chemical Sciences, University of Western Australia, 35 Stirling Highway, Crawley WA 6009, Western Australia; poates@ cyllene.uwa.edu.au

Accepted for publication 19 August 2003

\begin{abstract}
Background: Absorption of non-haeme iron occurs mainly in the duodenum. It involves the divalent metal transporter 1 (DMT1) in the uptake of ferrous Fe(II) iron and the basolateral transporter ferroportin/ IREG-1/MTP-1/SLC40A1 in its release. Whether ferroportin functions in this process at other sites in the enterocyte is unknown. In this study the effect of a blocking antibody to ferroportin on the uptake and release of iron was evaluated in enterocyte-like cells (IEC-6 and Caco-2) and in freshly isolated duodenal enterocytes from rats.

Methods: Uptake of $1 \mu \mathrm{M} \mathrm{Fe}(I I)$ and its release by cells was studied in the presence of the antibody. Ferroportin expression was determined by western blot analysis of duodenal mucosa enriched microvillus membranes, Caco-2 cells, IEC-6 cells, and freshly isolated enterocytes. Immunofluorescent detection of ferroporitn was performed on frozen sections of duodenum from rats with variations in body iron stores. Results: Ferroportin was expressed in all cell types. In these cells, the antibody significantly reduced $(p<0.05)$ uptake of Fe(II) by $40-50 \%$ but had no effect on the release of iron. In Caco- 2 cells, Fe(II) uptake was reduced only when the antibody was in contact with the apical membrane. Ferroportin protein was enriched in microvillus membrane preparations. In enterocytes from iron deficient rats, ferroportin was expressed along the brush border where it colocalised with lactase. Ferroportin was seen in the basal cytoplasm and along the basolateral membranes. Iron loading markedly reduced intracellular expression of ferroportin. In Caco-2 cells, ferroportin also localised to the microvillus and lateral and basal membranes.

Conclusions: In addition to release, ferroportin functions in the uptake of iron at the apical membrane, possibly by modulating the activity of DMT1.
\end{abstract}

n ron is an essential trace element that is required for numerous cellular functions but has the capacity to generate reactive oxygen species that can damage tissues. ${ }^{1}$ Therefore, adequate intake of iron is required to maintain the metabolic requirements of the individual. Matching iron supply to body iron requirements takes place at the level of iron absorption by duodenal enterocytes but despite extensive study, many of the details of the mechanism of iron absorption and the factors that regulate it remain unclear.

Recent studies have described the iron transport proteins divalent metal transporter $1(\mathrm{DMTl})^{23}$ and ferroportin/IREG-1/ metal transporter protein 1 (MTP1)/SLC40Al ${ }^{4-6}$ that are proposed to vectorially move iron across the apical and basolateral membranes of the enterocyte, respectively. DMTl is expressed on the apical membrane of the enterocyte, and in the presence of a proton gradient provided by gastric secretions it cotransports ferrous iron $(\mathrm{Fe}(\mathrm{II}))$ from the apical membrane into the cell. ${ }^{278}$ In addition, in microcytic anaemic mice and Belgrade rats, a G185R mutation in DMT1 greatly impairs the uptake of iron from the intestinal lumen, indicating the importance of DMT1 in iron uptake. ${ }^{39-11}$

In contrast, ferroportin/IREG-1/MTP1/SLC40Al, hereafter collectively referred to as ferroportin, is expressed predominately along the basolateral surfaces of duodenal enterocytes, suggesting a role in iron release. ${ }^{5}{ }^{12}$ Supporting this, expression systems have shown that ferroportin is involved in iron export in the presence of the ferroxidases ceruloplasmin ${ }^{4-6}$ or apotransferrin $^{5}$ but others showed release in the absence of these compounds. ${ }^{4}$ Also, over expression of ferroportin in HEK293T cells reduced ferritin synthesis and increased iron responsive protein activities, results that are consistent with depletion of cellular iron levels by way of increased release. ${ }^{4}$ In addition, separate studies have reported three mutations involving ferroportin that resulted in a haemochromatosislike phenotype. Two of these are missense mutations resulting in $\mathrm{N} 144 \mathrm{H}^{13}$ and $\mathrm{A} 77 \mathrm{D}^{14}$ while the third is a deletion of valine. ${ }^{15}$ It is unclear whether there is loss or gain of function of ferroportin ${ }^{16}$ but affected individuals present with iron overload of the reticuloendothelial system and subsequently the liver, suggesting that intestinal iron absorption is increased by these mutations.

In this study, we report the effect of a functional antibody against ferroportin activity by studying $\mathrm{Fe}(\mathrm{II})$ uptake and release, and ferroportin expression using isolated duodenal enterocytes, microvillus membranes from duodenal mucosa of rats, and the intestinal derived cell lines IEC- 6 and Caco-2.

\section{MATERIALS AND METHODS}

\section{Cell culture}

Intestinal epithelial cell line 6 (IEC-6) and Caco-2 cells were obtained from the American Type Culture Collection (Rockville, Maryland, USA). IEC-6 cells were grown and prepared as described previously. ${ }^{12}$ Caco- 2 cells were maintained in the presence of Dulbecco's modified Eagle's medium containing $15 \%$ fetal calf serum, $1 \%$ non-essential amino acids, $1 \%$ L-glutamine, $50 \mu \mathrm{g} / \mathrm{ml}$ penicillin, and $50 \mu \mathrm{g} /$ $\mathrm{ml}$ streptomycin, and used between passages 19 and 50 . Caco- 2 cells were seeded at a density of $1 \times 10^{4}$ cells $/ \mathrm{cm}^{2}$ onto cell culture inserts (pore size $0.4 \mu \mathrm{m}$; Falcon, Franklin Lakes, New Jersey, USA). The protein content of cells was measured

Abbreviations: DMT1, divalent metal transporter 1; MTP1, metal transporter protein $1 ; \mathrm{Fe}(I I)$, ferrous iron; IEC- 6 , intestinal epithelial cell line 6; BSS, buffered salt solution 
using a BCA protein assay kit in order to correct data for variation in cell number.

\section{Animals}

The Animal Welfare Committee of the University of Western Australia approved the use of animals in this study. Four week old male Wistar rats were fed semipurified diets ${ }^{17} 18$ low, normal, or high in iron to alter iron absorption. ${ }^{9}$ Two weeks later the rats were overdosed with $0.5 \mathrm{ml}$ of $60 \mathrm{~g} / \mathrm{l}$ Nembutal. The liver and small intestine were removed.

\section{Isolation of villus enterocytes}

The duodenum from rats fed normal levels of iron was removed and the enterocytes separated as previously described. ${ }^{19}$ Enterocytes from the mid-villus region were pooled, washed three times in phosphate buffered saline, and used immediately for the uptake of Fe(II). Viability of cells was assessed using phase contrast microscopy and trypan blue exclusion.

\section{Isolation of brush border membranes}

Brush border membranes were isolated from iron deficient duodenal mucosal scrapings. ${ }^{20}$ Microvillus membrane enrichment was determined by measurement of alkaline phosphatase activity. ${ }^{21}$

\section{Uptake of Fe(II) by IEC-6 cells and villus enterocytes}

IEC-6 cells in the exponential growth phase were used. ${ }^{12}$ Isolated enterocytes were resuspended in MEM to give $1 \times 10^{6}$ cells $/ \mathrm{ml}$, and $500 \mu \mathrm{l}$ of suspended cells were used at each time point. Cells were incubated with a 1:50 dilution of the ferroportin antibody ${ }^{12}$ (hereafter called the antibody) with or without $250 \mathrm{ng} / \mathrm{ml}$ of immunising peptide in the uptake medium for 30 minutes before and during the uptake of iron from $1 \mu \mathrm{M} \mathrm{Fe}(\mathrm{II})$. Cells were also incubated with preimmune serum.

To study the uptake of $\mathrm{Fe}(\mathrm{II})$, a solution containing $1 \mu \mathrm{M}$ iron as ${ }^{59} \mathrm{FeCl}_{3}$ and ${ }^{56} \mathrm{FeSO}_{4}$ in a 1:10 molar ratio, with a 100fold molar excess of freshly made sodium ascorbate, was added to an isotonic solution of MEM containing $20 \mathrm{mM}$ Hepes-Tris ( $\mathrm{pH} 5.5$ ) and $1 \%$ bovine serum albumin. IEC-6 cells were washed three times in buffered salt solution (BSS) to remove media and then incubated for up to 30 minutes in the $1 \mu \mathrm{M} \mathrm{Fe}(\mathrm{II})$ solution at $37^{\circ} \mathrm{C}$ in an atmosphere of $5 \% \mathrm{CO}_{2} /$ $95 \%$ air. Enterocytes were incubated at $37^{\circ} \mathrm{C}$ for up to 40 minutes in the $\mathrm{Fe}(\mathrm{II})$ solution. Cells were washed five times in BSS and lysed in 1\% Triton X-100/0.1 M NaOH and counted for radioactivity in a gamma counter (Packard, Connecticut, USA).

\section{Iron release from IEC- 6 cells and villus enterocytes}

IEC-6 cells and enterocytes were incubated with $1 \mu \mathrm{M}$ Fe(II) for one hour and then washed with BSS at $4^{\circ} \mathrm{C}$. After this they were incubated at $37^{\circ} \mathrm{C}$ for up to 30 minutes in BSS containing the antibody or preimmune serum. In this study, ceruloplasmin or apotransferrin were not used to study release because these compounds do not affect uptake or release of $\mathrm{Fe}(\mathrm{II})$ in these cells. ${ }^{12}$ Radiolabelled iron released into the media was measured following centrifugation. Cells were washed and lysed in $0.1 \mathrm{M} \mathrm{NaOH} / 1 \%$ Triton-X100 and counted for radioactivity. Release of iron is expressed as the percentage of the amount released from the cell compared with that taken up by the cell.

\section{$\mathrm{Fe}$ (II) uptake and release by Caco- 2 cells}

Caco- 2 cells were used 21 days later when confluent cultures of differentiated cells of a villus phenotype were obtained. This was determined using a millicell electrical resistance system (Millipore, Sydney, Australia).${ }^{22}$ Cells were used when the transepithelial electrical resistance exceeded $260 \Omega / \mathrm{cm}^{2}$ after subtraction of the resistance across a blank insert.

Cells were washed three times in BSS and incubated for up to one hour in the $1 \mu \mathrm{M} \mathrm{Fe}(\mathrm{II})$ solution in the apical chamber, as described above. Inserts were washed five times in BSS and the cells lysed. Radioactivity in the basal chamber and in Caco-2 cells was counted. Uptake represented the amount of radiolabelled iron in the cell plus that in the basal chamber, whereas release represented the radioactivity in the basal chamber. Preliminary studies using Caco-2 cells showed that ceruloplasmin or apotransferrin in the basal chamber had no affect on uptake. Therefore, these compounds were not used. Uptake and release of $\mathrm{Fe}(\mathrm{II})$ was studied with the antibody in the apical chamber. Also, following uptake of $\mathrm{Fe}$ (II) from the apical chamber for one hour, cells and both chambers were thoroughly washed and release of iron into the apical and basal chambers measured over 30 minutes.

\section{Immunofluorescent detection of ferroportin in whole duodenum and Caco- 2 cells}

Frozen sections of duodenum from an iron deficient and an iron loaded rat were sectioned at $7 \mu \mathrm{m}$, thawed to room temperature for five minutes, and then fixed in $4 \%$ buffered formal saline. The antibody was coincubated with monoclonal antibodies against either rat transferrin receptor or rat lactase $^{23}$ to reveal basolateral and apical membrane definition, respectively. ${ }^{12}$ The antibody had been incubated overnight in MEM or MEM plus $50 \mathrm{ng} / \mathrm{ml}$ of immunising peptide.

The antibody was placed in either the apical or basal chamber of viable Caco- 2 cells for 30 minutes at $4^{\circ} \mathrm{C}$. Cells were washed, fixed, and then incubated with rhodaminephalloidin 1:100 for 15 minutes to outline filamentous actin (Molecular Probes, Eugene, USA). In addition, cells were fixed and then immunoreacted with the antibody to reveal total ferroportin expression. Immunodetection was performed as described previously using species-specific fluorescent conjugated antibodies ${ }^{12}$ Sections were viewed on a confocal microscope (Biorad, Sydney, Australia, MRC 1000). Filamentous actin expression was used to outline the membranes of Caco-2 cells by confocal microscopy. After selecting a particular $\mathrm{z}$ plane, vertical serial sections of the entire cell were performed to determine ferroportin expression.

\section{Western blot analysis}

Protein from homogenised cells and enriched extracts of microvillus membrane were subjected to western blot analysis, as previously described. ${ }^{12}$ Rabbit polyclonal antirat ferroportin $(1: 3000),{ }^{12}$ polyclonal antimouse mA33 antibodies, considered a marker of basolateral membranes of enterocytes (1:2000), ${ }^{24}$ and an antirabbit secondary antibody conjugated to biotin (1:10000) (Serotech, Toronto, Canada) were used. The signal was amplified by the Vectastain ABC kit (Vector Laboratories, Burlingame, California, USA) and detected using an ECL chemiluminescent assay (Amersham, Bucks, UK). The western blots were analysed using Scion image (Scion Corporation, Frederick, Maryland, USA).

\section{Non-haeme iron assay}

Non-haeme iron content of the liver was measured by the method of Kaldor. ${ }^{25}$

\section{Statistical methods}

Results are expressed as means (SEM). Data were analysed by ANOVA and Tukey tests using the Instat program (Graphpad Software, San Diego, California, USA), or correlations were examined by linear regression methods using SPSS 8.0 statistical software (SPSS Inc., Illinois, USA). Differences were considered significant at $\mathrm{p}<0.05$. 


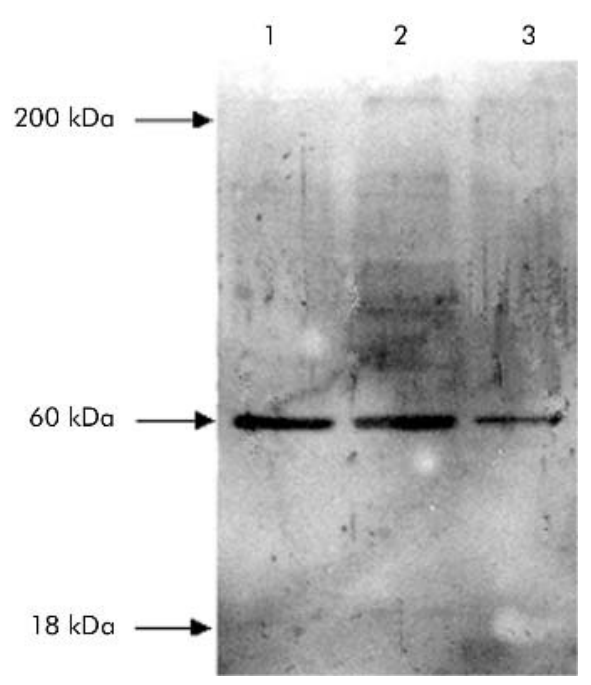

Figure 1 Western blot analysis showing expression of ferroportin, as evidenced by a single band migrating at $60 \mathrm{kDa}$ in rat IEC- 6 cells (lane 1), Caco-2 cells (lane 2), and freshly isolated enterocytes (lane 3).

\section{RESULTS}

Ferroportin is expressed in IEC-6 cells, Caco-2 cells, and isolated enterocytes

The ferroportin antibody detected one dominant band at $60 \mathrm{kDa}$ in IEC-6 cells, freshly isolated enterocytes, and Caco-2 cells (fig 1). The blot covers proteins ranging in weight from 206 to $15 \mathrm{kDa}$.

Uptake but not release of ferrous iron by IEC- 6 cells and rat enterocytes was reduced in the presence of the ferroportin antibody.

In IEC-6 cells the antibody reduced the uptake of $\mathrm{Fe}$ (II) by approximately $50 \%$ at all time points studied (fig $2 \mathrm{~A}$ ). This reduction was lost when the antibody was incubated with the immunising peptide (fig 2A). When IEC-6 cells were preloaded with iron and then incubated with the antibody, iron release was similar to controls (fig $2 \mathrm{~B}$ ).

When freshly isolated rat enterocytes were incubated with the antibody, uptake of $\mathrm{Fe}(\mathrm{II})$ was reduced by $40 \%$ (fig $3 \mathrm{~A}$ ). No difference was observed in the rate of release of iron in the presence or absence of antibody (fig 3B).
In Caco-2 cells, Fe(II) uptake is reduced in the presence of the ferroportin antibody

When the ferroportin antibody and Fe(II) were placed in the apical chamber, $\mathrm{Fe}(\mathrm{II})$ uptake was inhibited by $50 \%$ (fig $4 \mathrm{~A}$ ). However, the rate of release was not affected (fig 4B). Radiolabelled iron was released into the basal chamber only and did not re-enter the apical chamber once taken up (fig 4C).

\section{Localisation of ferroportin in duodenal enterocytes and Caco- 2 cells}

There was a 35 -fold difference in liver iron stores between iron deficient ( $7 \mu \mathrm{g} / \mathrm{g}$ liver weight) and iron loaded $(243 \mu \mathrm{g} / \mathrm{g}$ liver weight) rats.

In iron deficient enterocytes, the strongest ferroportin expression was seen along the basal and lateral membranes of the enterocyte as well as in the basal cytoplasm (fig 5A, D). Transferrin receptor was used as a marker of basolateral membranes, basal cytoplasm, and of the supranuclear region (fig 5B). At these sites there was strong overlap with ferroportin (fig 5C). As expected, transferrin receptor expression was not seen along the apical membrane (fig 5B). Ferroportin was expressed along the apical membrane (fig 5A,C, D). This was confirmed when the microvillus membrane marker lactase (fig 5E) colocalised with ferroportin (fig 5F).

Compared with iron deficient tissue, iron loading reduced ferroportin expression most notably in the basal cytoplasm and along the basolateral membranes (data not shown).

Ferroportin expression was not seen when tissues were coincubated with the immunising peptide (data not shown).

In viable Caco-2 cells exposed to the antibody in the apical media, ferroportin expression was only on microvilli (fig $5 G$ ). Caco-2 cells fixed before immunodetection revealed strong ferroportin expression in the apical cytoplasm and lateral membrane (fig $5 \mathrm{H}$ ). When the antibody was placed in the basal chamber, ferroportin expression was seen as $0.4 \mu \mathrm{m}$ diameter discs of fluorescence on the basal membrane. This pattern was consistent with the diameter of the pores in the insert allowing contact between the antibody and basal membrane (fig 5I)

\section{Ferroportin is enriched in brush border membranes of duodenal enterocytes}

Enrichment of brush border membrane preparations was evidenced by a sixfold higher alkaline phosphatase activity compared with the starting homogenate. In brush border membranes, expression of ferroportin was enriched twofold
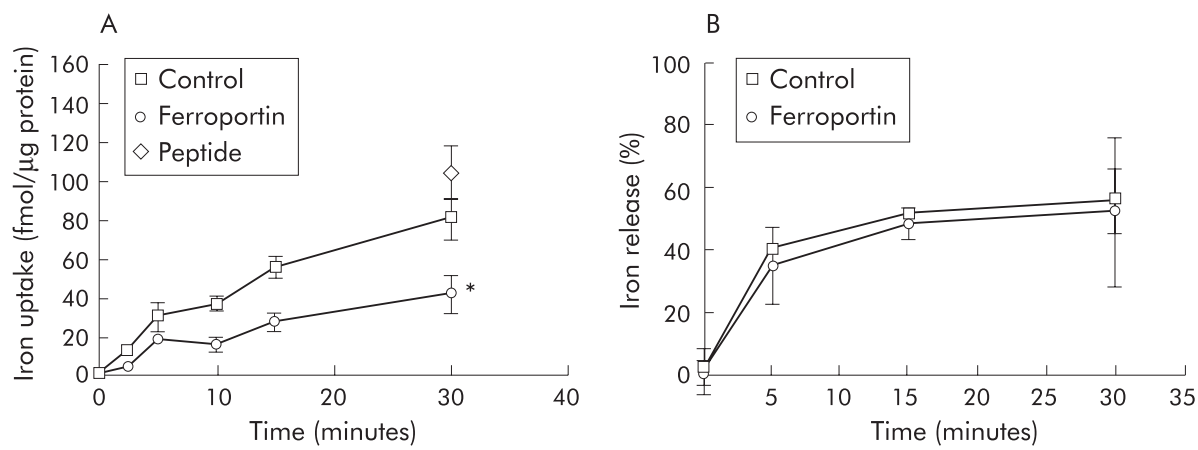

Figure 2 Iron uptake and release by IEC-6 cells in the presence of a ferroportin antibody. (A) IEC-6 cells were incubated with the antibody (Ferroportin) alone, antibody in combination with $250 \mathrm{ng} / \mathrm{ml}$ immunising peptide (Peptide, 30 minutes only), or preimmune serum (Control) for 30 minutes prior and then during the period of uptake from $1 \mu \mathrm{M}$ ferrous iron (Fe(II)). (B) Release of radiolabelled iron following loading of cells with $1 \mu \mathrm{M} \mathrm{Fe}(I I)$. The antibody or preimmune serum was present only during the release phase. Values are means (SEM), $n=3$. * $p<0.05$ compared with controls at all time points. 


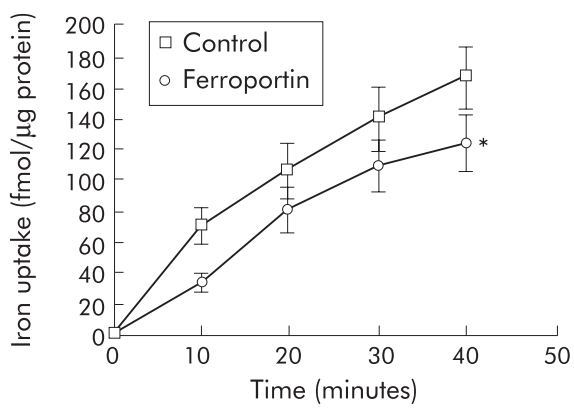

B

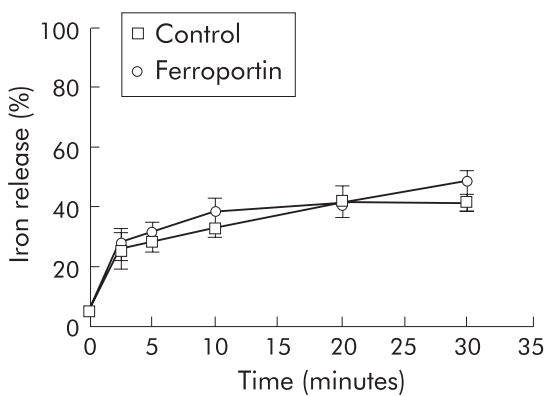

Figure 3 Effect of an ferroportin antibody on iron uptake (A) and release (B) by freshly isolated rat duodenal enterocytes (see fig 2 for details). $n=9$.

(fig 6, $60 \mathrm{kDa}$ ) while mA33 (fig 6, $40 \mathrm{kDa}$ ), a marker of enterocyte basolateral membranes, was reduced fourfold compared with starting homogenate.

\section{DISCUSSION}

Before studying the functional effects of an antibody against ferroportin, we tested its specificity in four ways. Firstly, protein obtained from IEC-6 cells, freshly isolated enterocytes, and Caco-2 cells subjected to western blot analysis showed one dominant band of the predicted size from the cDNA encoding ferroportin. ${ }^{4-6}$ Secondly, cellular over expression of ferroportin resulted in the detection of a band of the appropriate size that was not amplified in non-transfected cells. ${ }^{12}$ Thirdly, the immunofluorescent detection of ferroportin was lost when the antibody was preincubated with the immunising peptide used to produce the antibody (see below). Fourthly, loss of functional activity produced by the antibody was restored when it was coincubated with the immunising peptide (see below). Thus we conclude that the antibody produced is specific for ferroportin.

This antibody was generated using a peptide sequence predicted to be in the middle of the largest extracellular domain, spanning transmembrane domains 3 and 4 . Previously, we showed by immunofluorescence that there was an extracellular interaction with the antibody and ferroportin, as evidenced by its localisation to the cell surface of viable cells. ${ }^{12}$ This extracellular interaction therefore enabled us to evaluate the functional effect of blocking a defined region of ferroportin on the uptake and release of $\mathrm{Fe}(\mathrm{II})$ in IEC-6 cells, freshly isolated enterocytes, and Caco-2 cells. Surprisingly, we showed in polarised enterocytes and non-polarised IEC-6 cells that the ferroportin antibody specifically reduced the uptake of $\mathrm{Fe}(\mathrm{II})$ but had no effect on its release. However, it is unclear whether the effect of the antibody on uptake is due to an interaction with ferroportin at the apical or basolateral membrane because both surfaces are exposed to the antibody during the study. Therefore, we used polarised Caco-2 cells grown on bicameral inserts and showed that when the antibody interacts with the apical membrane, uptake of Fe(II) was inhibited. Although three of the 18 amino acids differ in the rat and human ferroportin sequence used to generate the antibody, the similar degree of inhibition in uptake seen with rodent cells (isolated enterocytes and IEC-6 cells) and human derived Caco-2 cells suggests that a conserved region in ferroportin is important when interacting with the antibody.

If ferroportin functions in the uptake of iron then it must be present along the microvillus membrane. To test this we prepared microvillus membrane protein from duodenal mucosa and measured ferroportin expression by western blot analysis. Enrichment of microvillus membrane protein was confirmed by increased alkaline phosphatase activity, and by a concomitant reduction in expression of the basolateral membrane protein $\mathrm{mA} 33^{24}$ compared with the starting homogenate. Under these conditions ferroportin expression was increased indicating its presence along the microvillus membrane of duodenal enterocytes.

This finding differs from previous immunofluorescent studies, including one from our laboratory which did not localise ferroportin to the microvillus membrane using low power imaging. ${ }^{4-6}$ In view of this we re-evaluated expression of ferroportin by confocal microscopy in iron loaded and iron deficient duodenum with emphasis on expression at the microvillus membrane of enterocytes. When using high power imaging, ferroportin was seen on the microvilli. This was confirmed when lactase, a microvillus membrane marker, colocalised with ferroportin. When ferroportin distribution was studied in iron loaded tissue, intracellular expression was diminished compared with iron deficient tissue, consistent with the regulation of ferroportin by body
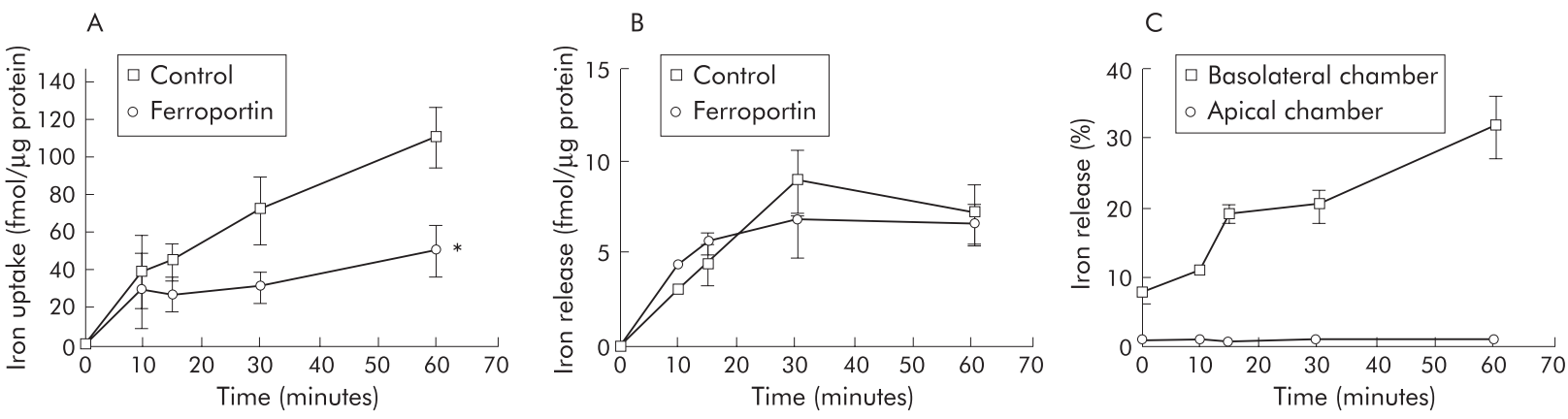

Figure 4 Effect of a ferroportin antibody on the uptake of $1 \mu \mathrm{M}$ ferrous iron (Fe(III)) and its release by Caco-2 cells. (A) Iron plus antibody (Ferroportin) or preimmune serum (Control) in the apical chamber, and iron release into the basal chamber (B). (C) Release of radiolabelled iron into the apical or basal chamber following loading of cells with iron in the apical chamber. $n=3$. * $p<0.05$ compared with control from 15 to 60 minutes. 

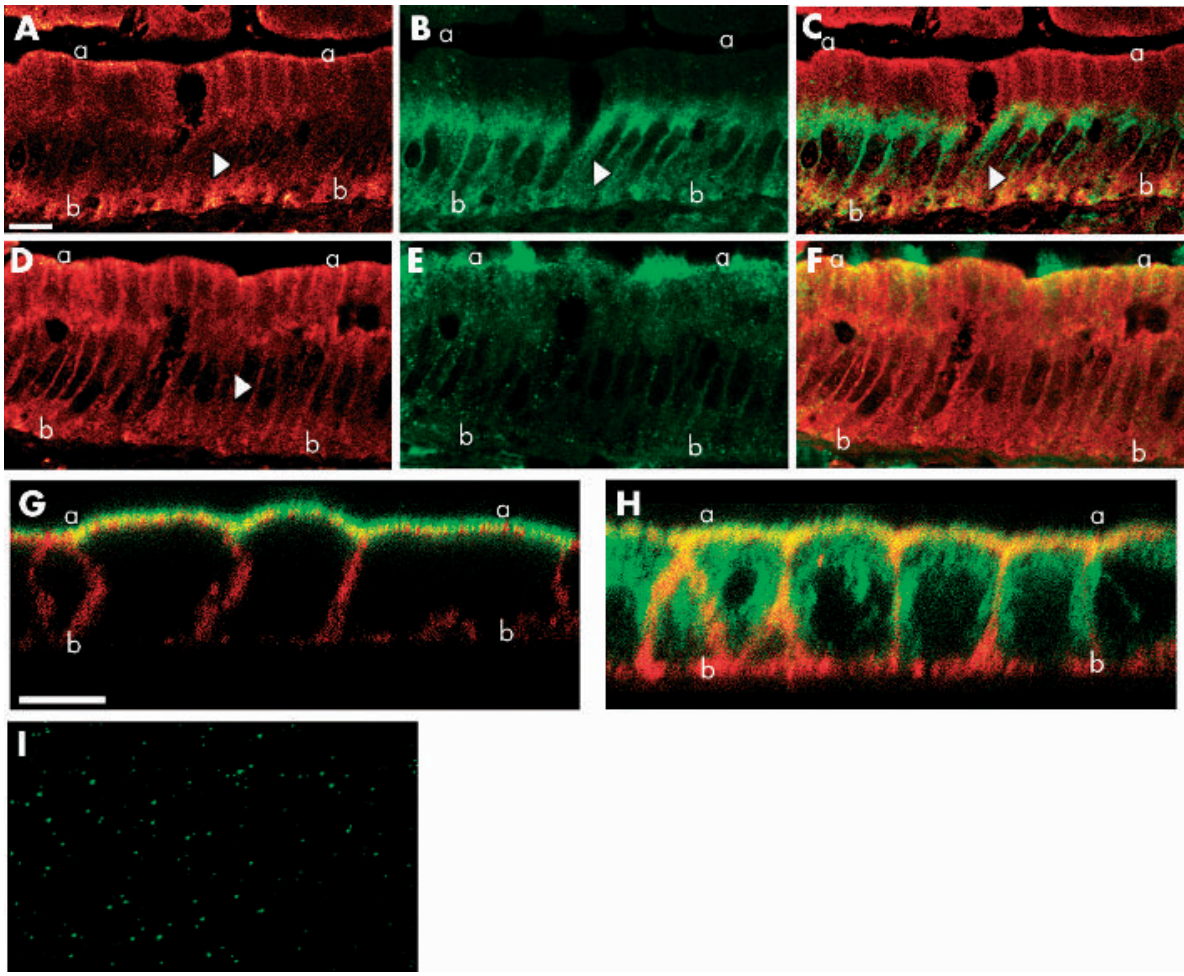

Figure 5 Ferroportin expression in the duodenum ( $A, C, D, F=$ red fluorescence) of an iron deficient rat and in viable (G, I) and fixed Caco-2 cells $(\mathrm{H}=$ green fluorescence). Expression of transferrin receptor $(A-C)$ and lactase $(D-F)$. In duodenal tissue, ferroportin expression localised predominately to the basal (b) and lateral membranes (arrow) but was also present on the apical membrane (a). Transferrin receptor (B, C) localised to the basal membrane (b), lateral membranes (arrow), and supranuclear region (above arrow), and at these sites overlapped with ferroportin expression (yellow in (C)). Lactase (E, F) localised to the apical (microvillus) membrane (a) and colocalised with ferroportin at this site (yellow in (F)). In viable Caco-2 cells when the antibody was in the apical chamber, expression was seen on microvilli (a). As the antibody could not penetrate the cell membrane, intracellular expression (green fluorescence) was not detected. (G) In prefixed Caco-2 cells, ferroportin localised to the basal and lateral membranes and apical cytoplasm (C). Filamentous actin fluoresced red and was used to outline Caco-2 cells and overlap with ferroportin fluoresced yellow. (I) When the antibody was placed in contact with the basal chamber and the basal membrane viewed from above, ferroportin fluoresced as $0.4 \mu \mathrm{m}$ disks. Scale bars $=10 \mu \mathrm{m}$.

iron stores. ${ }^{4-626}$ Furthermore, ferroportin expression was detected on the extracellular domain of microvillus membrane using viable Caco-2 cells. However, McKie and colleagues, ${ }^{6}$ using epitope tagged ferroportin, did not observe expression along the apical membrane of Caco-2 cells. This might be due to either failure of the fusion protein to target the apical membrane, or the amount expressed was below detectable levels.

Based on the evidence provided above, we propose that ferroportin is present on the apical membrane and is involved in the absorption of $\mathrm{Fe}(\mathrm{II})$. It is unlikely that ferroportin functions as the uptake transporter because there is convincing evidence that this is via DMTl. ${ }^{2}$ It is also unlikely that ferroportin functions to release excess iron at the apical membrane because no iron internalised by Caco- 2 cells was released back into the apical chamber. It is possible that ferroportin modulates the expression and/or activity of DMTl

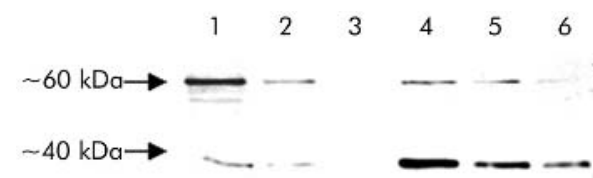

Figure 6 Western blot analysis of ferroportin $(60 \mathrm{kDa})$ and the basolateral membrane marker of enterocytes, mA33 (40 kDa), in duodenal brush border membranes (lanes 1-3) and the starting homogenate (lanes 4-6). Lanes 1, 4=80 $\mu \mathrm{g}$, lanes $2,5=40 \mu \mathrm{g}$, and lanes $3,6=20 \mu \mathrm{g}$ of protein. $\mathrm{n}=9$ rats. at the apical surface and that this in turn leads to altered iron uptake. If this is true then it suggests that in addition to an involvement in iron efflux, ferroportin also functions as a modulator of iron uptake on the apical membrane. Although we attempted to determine an effect of the antibody at the basal membrane of Caco-2 cells we did not see a response. This in part may be due to the limited exposure of the basal membrane to the basal media with the inserts used. None the less, ferroportin is expressed on the basal membrane and the antibody makes contact with this surface, as evidenced by fluorescent disks with dimensions similar in diameter to the pores within the inserts. This finding is consistent with McKie and colleagues ${ }^{6}$ who noted using computer generated vertical sections through a monolayer of Caco-2 cells that ferroportin expression was along the lateral membrane and on the basal membrane. As the antibody did not affect efflux when present in the basal chamber, this is consistent with that obtained with IEC- 6 cells and freshly isolated polarised enterocytes. These observations may give insight into the nature of the interaction. We hypothesise that at the apical membrane ferroportin may interact with another protein such as DMTl and that the antibody interferes with this interaction resulting in decreased uptake. Because DMTl is not expressed on the basal and lateral membranes this interaction does not take place and therefore release is not affected in the presence of the antibody.

\section{ACKNOWLEDGEMENTS}

A grant from the national health and medical research council of Australia supported this work. We thank Evan Morgan for helpful 
discussions, Alan Light for technical assistance, Joan Heath for the mA33 antibody, and Andreas Quaroni for the lactase antibody.

\section{Authors' affiliations}

C Thomas, P S Oates, Physiology School of Biomedical and Chemical Sciences, University of Western Australia, Crawley, Western Australia

\section{REFERENCES}

1 Andrews NC. Intestinal iron absorption: current concepts circa 2000. Dig Liver Dis 2000:32:56-61.

2 Gunshin H, Mackenzie B, Berger UV, et al. Cloning and characterization of a mammalian proton-coupled metal-ion transporter. Nature 1997;388:482-8.

3 Fleming MD, Trenor CC iii, Su MA, et al. Microcytic anaemia mice have a mutation in Nramp2, a candidate iron transporter gene. Nat Genet 1997; 16:383-6.

4 Abboud S, Haile DJ. A novel mammalian iron-regulated protein involved in intracellular iron metabolism. J Biol Chem 2000;275:19906-12.

5 Donovan A, Brownlie A, Zhou Y, et al. Positional cloning of zebrafish ferroportin 1 identifies a conserved vertebrate iron exporter. Nature 2000;403:776-81

6 McKie AT, Marciani P, Rolfs A, et al. A novel duodenal iron-regulated transporter, IREG1, implicated in the basolateral transfer of iron to the circulation. Mol Cell 2000:5:299-309.

7 Trinder D, Oates PS, Thomas C, et al. Localisation of divalent metal transporter 1 (DMT1) to the microvillus membrane of rat duodenal enterocytes in iron deficiency, but to hepatocytes in iron overload. Gut 2000;46:270-6.

8 Tandy S, Williams M, Leggett A, et al. Nramp2 expression is associated with $\mathrm{pH}$-dependent iron uptake across the apical membrane of human intestinal Caco-2 cells. J Biol Chem 2000;275:1023-9.

9 Oates PS, Morgan EH. Defective iron uptake by the duodenum of Belgrade rats fed diets of different iron contents. Am J Physiol 1996;270:G826-32.

10 Fleming MD, Romano MA, Su MA, et al. Nramp2 is mutated in the anemic Belgrade (b) rat: evidence of a role for Nramp2 in endosomal iron transport. Proc Natl Acad Sci U S A 1998;95:1148-53.

11 Oates PS, Thomas C, Freitas E, et al. Gene expression of divalent metal transporter 1 and transferrin receptor in duodenum of Belgrade rats. Am J Physiol Gastrointest Liver Physiol 2000;278:G930-6.

12 Thomas C, Oates PS. IEC-6 cells are an appropriate model of intestinal iron absorption in rats. J Nutr 2002;132:680-7.
13 Niajou OT, Vaessen $N$, Joosse $M$, et al. A mutation in SLC11A3 is associated with autosomal dominant hemochromatosis. Nat Genet 2001;28:213-14.

14 Montosi G, Donovan A, Totaro A, et al. Autosomal-dominant hemochromatosis is associated with a mutation in the ferroportin (SLC11A3) gene. J Clin Invest 2001;108:619-23.

15 Roetto A, Merryweather-Clarke AT, Daraio F, et al. A valine deletion of ferroportin 1: a common mutation in hemochromastosis type 4. Blood 2002; 100:733-4.

16 Fleming RE, Sly WS. Ferroportin mutation in autosomal dominant hemochromatosis: loss of function, gain in understanding. J Clin Invest 2001; 108:521-2.

17 Bieri JG, Stoewsand GS, Briggs GM, et al. Report of the American Institute of Nutrition Ad Hoc committee on standards for nutritional studies. J Nutr 1977; 107:1340-8.

18 Oates PS, Morgan EH. Effects of dietary iron loading with carbonyl iron and of iron depletion on intestinal growth, morphology, and expression of transferrin receptor in the rat. Anat Rec 1996;246:364-71.

19 Oates PS, Thomas C, Morgan EH. Characterization of isolated duodenal epithelial cells along a crypt-villus axis in rats fed diets with different iron content. J Gastroenterol Hepatol 1997; 12:829-38.

20 Will PC, Hopfer U. Apparent inhibition of active non-electrolyte transport by an increased sodium permeability of the plasma membrane. Mechanism of action of p-chloromercuribenzene sulfonate. J Biol Chem 1979;254:3806-11.

21 Weiser MM. Intestinal epithelial cell surface membrane glycoprotein synthesis. I. An indicator of cellular differentiation. J Biol Chem 1973;248:2536-41.

22 Pinto M, Robine-Leon S, Appay MD, et al. Enterocyte-like differentiation and polarization of the human colon carcinoma cell line Caco-2 in culture. Biol Cell 1983;47:323-30

23 Quaroni A, Isselbacher KJ. Study of intestinal cell differentiation with monoclonal antibodies to intestinal cell surface components. Dev Biol 1985;111:267-79.

24 Johnstone CN, Tebbutt NC, Abud HE, et al. Characterization of mouse A33 antigen, a definitive marker for basolateral surfaces of intestinal epithelial cells. Am J Physiol Gastrointest Liver Physiol 2000;279:G500-10.

25 Kaldor I. Studies on intermediary iron metabolism. V. The measurement of nonhaemoglobin tissue iron. Aust J Exp Biol Med Sci 1954;32:795-800.

26 Frazer DM, Wilkins SJ, Becker EM, et al. A rapid decrease in the expression of DMT1 and Dcytb but not Iregl or hephaestin explains the mucosal block phenomenon of iron absorption. Gut 2003;52:340-6. 